\title{
Calcitonin gene-related peptide promotes the expression of osteoblastic genes and activates the WNT signal transduction pathway in bone marrow stromal stem cells
}

\author{
RI ZHOU ${ }^{1}$, ZHI YUAN ${ }^{1}$, JIERONG LIU ${ }^{2}$ and JIAN LIU ${ }^{1}$ \\ Departments of ${ }^{1}$ Orthopedics and ${ }^{2}$ Radiology, Xijing Hospital, Fourth Military Medical University, \\ Xi'an, Shaanxi 710032, P.R. China
}

Received April 3, 2015; Accepted January 15, 2016

DOI: $10.3892 / \mathrm{mmr} .2016 .5117$

\begin{abstract}
Calcitonin gene-related peptide (CGRP) is known to induce osteoblastic differentiation and alkaline phosphatase activity in bone marrow stromal stem cells (BMSCs). However, it has remained elusive whether this effect is mediated by CGRP receptors directly or whether other signaling pathways are involved. The present study assessed the possible involvement of the $\mathrm{Wnt} / \beta$-catenin signaling pathway in the activation of CGRP signaling during the differentiation of BMSCs. First, the differentiation of BMSCs was induced in vitro and the expression of CGRP receptors was examined by western blot analysis. The effects of exogenous CGRP and $\mathrm{LiCl}$, a stimulator of the $\mathrm{Wnt} / \beta$-catenin signaling pathway, on the osteoblastic differentiation of BMSCs were assessed; furthermore, the expression of mRNA and proteins involved in the Wnt/ $\beta$-catenin signaling pathway was assessed using quantitative PCR and western blot analyses. The results revealed that CGRP receptors were expressed throughout the differentiation of BMSCs, at days 7 and 14. Incubation with CGRP and $\mathrm{LiCl}$ led to the upregulation of the expression of osteoblastic genes associated with the Wnt/ $\beta$-catenin pathway, including the mRNA of c-myc, cyclin D1, Lef1, Tcf7 and $\beta$-catenin as well as $\beta$-catenin protein. However, the upregulation of these genes and $\beta$-catenin protein was inhibited by CGRP receptor antagonist or secreted frizzled-related protein, an antagonist of the Wnt/ $\beta$-catenin pathway. The results of the present study therefore suggested that the Wnt/ $\beta$-catenin signaling pathway may be involved in CGRP- and $\mathrm{LiCl}$-promoted osteoblastic differentiation of BMSCs.
\end{abstract}

Correspondence to: Professor Jian Liu, Department of Orthopedics, Xijing Hospital, Fourth Military Medical University, 127 West Changle Road, Xi'an, Shaanxi 710032, P.R. China E-mail: jianliu321545@yeah.net

Key words: calcitonin gene-related peptide, Wnt signal transduction pathway, differentiation, bone marrow stromal stem cells

\section{Introduction}

Skeletal sensory neurons form the source of a network innervating cancellous bone. They produce various neurotransmitters, including calcitonin gene-related peptide (CGRP), somatostatin and substance P $(1,2)$. CGRP is a neuropeptide produced in specific neurons by alternative splicing of the primary transcript from the calcitonin gene and has important functions in numerous physiological and pathological processes. The CGRP receptor complex, which is expressed in osteoblasts, is a dimeric complex of the $G$ protein-coupled calcitonin receptor-like receptor (CRL) and G protein-coupled activity modifying protein 1 (RAMP1), a receptor activity-modifying protein, which are required for physiological activation by CGRP. CRL and RAMP1 receptors are expressed in mature osteoblasts (3-10). Numerous studies have demonstrated that CGRP innervation is associated with bone formation in vivo and that CGRP stimulates the differentiation of bone marrow stromal stem cells (BMSCs) into osteoblasts in vitro (2,11-14). Further studies supported the bone-building action of CGRP by demonstrating that transgenic mice show increased bone formation and trabecular bone mass following overexpression of CGRP in their osteoblasts, while CGRP-deficient mice displayed a decreased bone formation rate and accelerated bone loss $(4,15,16)$. These studies suggested that CGRP has an important role in maintaining bone formation in skeletal tissues; however, its mechanism of action in osteoblastogenesis and osteoblasts has largely remained elusive.

Canonical Wnt signaling is one of three independent Wnt pathways activated by a receptor complex of Frizzled $(\mathrm{Fz})$, which is referred to as the Wnt/ $\beta$-catenin signaling pathway. The regulation of cytoplasmic $\beta$-catenin is a key step in numerous cellular signal transductions $(17,18)$. In the Wnt/ $\beta$-catenin signaling pathway, the receptors binding to canonical Wnts include 7-transmembrane domain-spanned Fz receptor and low-density lipoprotein 5 and -6 (LRP5/6) co-receptors (19-21). The scaffolding protein Dishevelled interacts with the destruction complex consisting of the scaffold protein Axin, which binds two other key components, adenomatous polyposis coli and glycogen synthase kinase-3, leading to the dephosphorylation of $\beta$-catenin and subsequent 
translocation into the nucleus (22-25). Accumulation of $\beta$-catenin in the cytoplasm and nuclear localization are crucial for the activation of the Wnt pathway. Transcription factors binding with the $\beta$-catenin protein and activating Wnt-associated genes include cyclin D1 and c-myc (26). Secreted Fz-related protein (sFRP), which antagonizes the interactions between Wnts and frizzled receptors, can inhibit the Wnt/ $\beta$-catenin signaling pathway (27). Over the past few years, the Wnt/ $\beta$-catenin-signaling pathway has been shown to be an important regulatory factor in bone metabolism $(21,28-30)$; however, the involvement of the canonical Wnt/ $\beta$-catenin signaling pathway in CGRP-mediated osteogenic processes has remained to be demonstrated, which was the purpose of the present study.

\section{Materials and methods}

Isolation of BMSCs. The study was approved by the ethics committee of the Laboratory Animal Center of the Fourth Military Medical University (Xi'an, China). Rats were supplied by the Laboratory Animal Center of the Fourth Military Medical University, and sacrificed by $\mathrm{CO}_{2}$ asphyxiation. Rat BMSCs were isolated from the bone marrow of male rats ( $\mathrm{n}=8$; age, 6 weeks; weight, 80-100 g), which was obtained by flushing the femoral and tibial medullary cavities with ice-cold low-glucose Dulbecco's modified Eagle's medium (L-DMEM; Gibco; Thermo Fisher Scientific, Inc., Waltham, MA, USA) supplemented with $10 \%$ fetal bovine serum (FBS; Gibco). The marrow cell suspension was repeatedly aspirated through a 22-gauge needle and filtered through a $100-\mu \mathrm{m}$ cell strainer prior to culture (both purchased from Corning, Inc., New York, NY, USA). Marrow cells were plated in $25-\mathrm{cm}^{2}$ tissue culture flasks at a density of $1 \times 10^{6}-1 \times 10^{7}$ cells $/ \mathrm{ml}$. The cultures were incubated at $37^{\circ} \mathrm{C}$ in a humidified atmosphere containing $5 \%$ $\mathrm{CO}_{2}$. The media was comprised of L-DMEM supplemented with $10 \% \mathrm{FBS}, 100 \mathrm{IU} / \mathrm{ml}$ penicillin, $100 \mu \mathrm{g} / \mathrm{ml}$ streptomycin and $1 \mu \mathrm{g} / \mathrm{ml}$ amphotericin, and was replaced every two days.

Monolayer culture. When the cell confluence reached $80 \%$, cells were passaged by detachment with $0.02 \%$ trypsin (Gibco) and subcultured in a fresh flask at a ratio of 1:2. The cells were cultured in flasks and three passages of monolayer cells were divided into 24-well culture plates. At passage 3, the cells were divided into two groups: The osteogenic induction group, which was further cultured in differentiation medium (L-DMEM containing $10 \mathrm{mM} \beta$-glycerophosphate, $100 \mathrm{~nm}$ dexamethasone and $50 \mu \mathrm{g} / \mathrm{ml}$ ascorbic acid (Sigma-Aldrich, St. Louis, MO, USA) to induce osteogenic differentiation (31), and the control group, which was cultured in normal medium. To detect the expression of CGRP receptors in the process of differentiation, the cells in the induction group were further divided into four groups, which were then treated with various concentrations of $\operatorname{CGRP}\left(0,10^{-12}, 10^{-10}\right.$ and $\left.10^{-8} \mathrm{M}\right)$ to determine the optimal concentration to promote cellular differentiation. In another experiment, cells from the induction group were divided into five groups to determine the effects of CGRP receptor antagonist and SFRP on the differentiation of BMSCs: i) The control group was treated with phosphate-buffered saline; ii) cells were incubated with $20 \mathrm{mM} \mathrm{LiCl}$ (Sigma-Aldrich); iii) cells were incubated with CGRP $\left(10^{-8} \mathrm{M}\right)$; iv) cells were
Table I. Sequences of the primers used for polymerase chain reaction.

\begin{tabular}{|c|c|c|}
\hline Gene & Sequence $\left(5^{\prime}-3^{\prime}\right)$ & $\begin{array}{l}\text { Predicted } \\
\text { length }(b p)\end{array}$ \\
\hline RAMP1 & $\begin{array}{l}\text { F: ACGTGAAGAGGGTGCTGTCT } \\
\text { R: CACCCCAAAGTGCTTTGATT }\end{array}$ & 235 \\
\hline ALP & $\begin{array}{l}\text { F: CCTTGAAAAATGCCCTGAAA } \\
\text { R: CTTGGAGAGAGCCACAAAGG }\end{array}$ & 191 \\
\hline $\mathrm{OCN}$ & $\begin{array}{l}\text { F: CATGAGGACCCTCTCTCTGC } \\
\text { R: AGGTAGCGCCGGAGTCTATT }\end{array}$ & 153 \\
\hline COL1 & $\begin{array}{l}\text { F: TGGTCCTCAAGGTTTCCAAG } \\
\text { R: TTACCAGCTTCCCCATCATC }\end{array}$ & 123 \\
\hline RUNX2 & $\begin{array}{l}\text { F: GAGCTACGAAATGCCTCTGC } \\
\text { R: GGACCGTCCACTGTCACTTT }\end{array}$ & 173 \\
\hline CCND1 & $\begin{array}{l}\text { F: GCGTACCCTGACACCAATCT } \\
\text { R: CTCTTCGCACTTCTGCTCCT }\end{array}$ & 180 \\
\hline C-MYC & $\begin{array}{l}\text { F: GCTCCTCGCGTTATTTGAAG } \\
\text { R: TTCTCTTCCTCGTCGCAGAT }\end{array}$ & 152 \\
\hline$\beta$-CATEI & $\begin{array}{l}\text { F: CTCCCCTGACAGAGTTGCTC } \\
\text { R: ATGTCCAGTCCGAGATCAGC }\end{array}$ & 187 \\
\hline TCF7 & $\begin{array}{l}\text { F: GCACGGGATAACTACGGAAA } \\
\text { R: AAAGCGAGCACGACATTTCT }\end{array}$ & 99 \\
\hline LEF1 & $\begin{array}{l}\text { F: TAACAAGGGCCCCTCCTACT } \\
\text { R: CCTGGAGAAAAGTGCTCGTC }\end{array}$ & 198 \\
\hline GAPDH & $\begin{array}{l}\text { F: ATTGTCAGCAATGCATCCTG } \\
\text { R: ATGGACTGTGGTCATGAGCC5 }\end{array}$ & 102 \\
\hline
\end{tabular}

F, forward; R, reverse.

incubated with a mixture of CGRP $\left(10^{-8} \mathrm{M}\right)$ and $10^{-6} \mathrm{M} \mathrm{CGRP}$ receptor antagonist CGRP8-37 (Sigma-Aldrich); v) cells were incubated with a mixture of CGRP $\left(10^{-8} \mathrm{M}\right)$ and $10 \mu \mathrm{g} / \mathrm{ml}$ sFRP (R\&D Systems, Inc. Minneapolis, MN, USA).

Alizarin red staining. Alizarin red staining was performed to identify osteoblasts. After three passages of monolayer culture, cells were cultured in differentiation medium for 14 days and then fixed in $4 \%$ paraformaldehyde (Sigma-Aldrich) for $30 \mathrm{~min}$, followed by three washes with ice-cold phosphate-buffered saline and staining for $5 \mathrm{~min}$ with alizarin red (Sigma-Aldrich). The cells were viewed using a 450 fluorescent inverted phase contrast microscope (Nikon Corporation, Tokyo, Japan).

Reverse-transcription quantitative polymerase chain reaction $(R T q P C R)$. To assess the expression of various genes in BMSCs in the experimental groups, total RNA was isolated from the cells using TRIzol (Invitrogen; Thermo Fisher Scientific, Inc.) and cDNA synthesis was performed using Oligo dT (Invitrogen). The qPCR assay was performed using SYBER Green (Applied Biosystems; Thermo Fisher Scientific, Inc.) with the primers (Shanghai GenePharma Co., Ltd., Shanghai, China) designed with Primer Express software (version 3.0; Applied Biosystems), listed in Table I. The amplification 

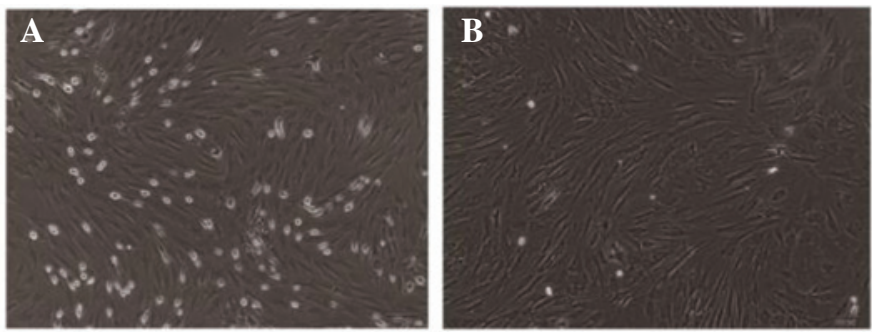

$\mathbf{E}$

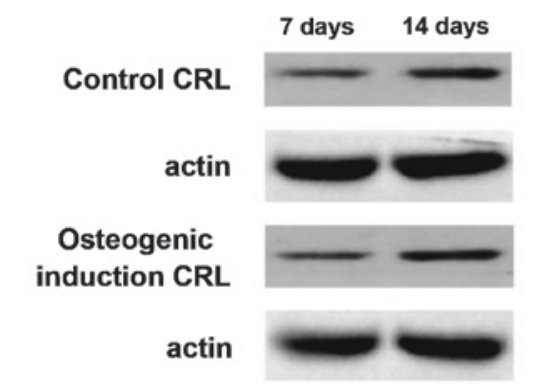

$\mathbf{F}$

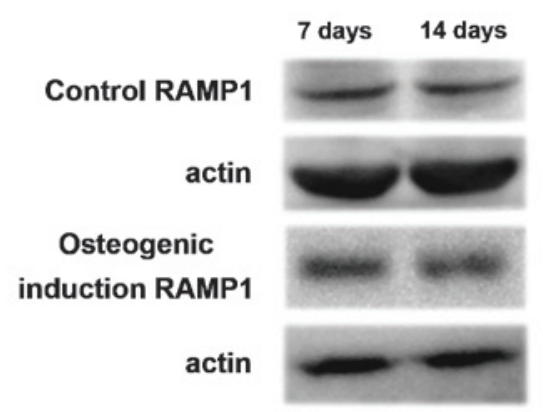

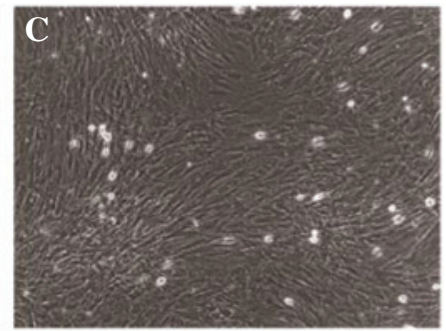

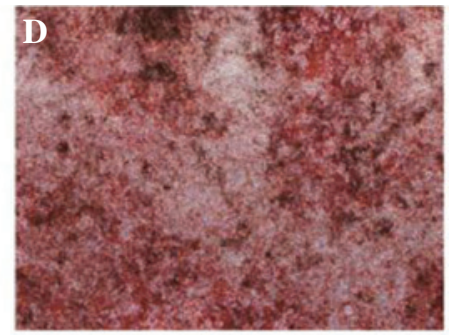

CRL protein
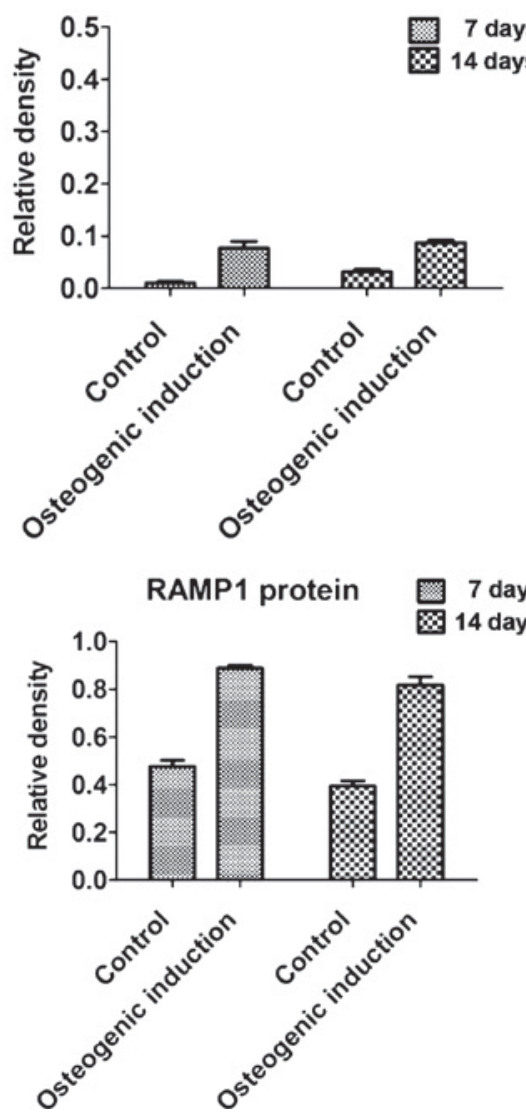

Figure 1. Microscopic images of BMSCs at (A) the primary passage, (B) the third passage, (C) 7 days after differentiation in the osteogenic medium (magnification, x100). (D) Differentiated osteogenic cells stained with alizarin red (magnification, $x 40$ ). The protein expression of (E) CRL and (F) RAMP1 was detected by western blot analysis at days 7 and 14 . Values are expressed as the mean \pm standard error of the mean. BMSC, bone marrow stromal stem cell; CRL, calcitonin receptor-like receptor; RAMP1, receptor (G protein-coupled) activity modifying protein 1.

conditions were as follows: $95^{\circ} \mathrm{C}$ for $3 \mathrm{~min}$, followed by 40 cycles of $95^{\circ} \mathrm{C}$ for $15 \mathrm{sec}$ and $60^{\circ} \mathrm{C}$ for $30 \mathrm{sec}$. Thermal cycling and fluorescence detection were performed using the StepOnePlus $^{\mathrm{TM}}$ Real-Time PCR System (Applied Biosystems). The mRNA levels of alkaline phosphatase, collagen type I, osteocalcin, Runx2, c-myc, cyclin D1, Lef1, Tcf7 and $\beta$-catenin mRNA were calculated relative to those of GAPDH using the $\Delta \Delta \mathrm{Ct}$ method (32). Experiments were performed in triplicate.

Protein extraction and western blot analysis. Following 7 and 14 days of treatment, the cells in the experimental groups were subjected to protein extraction with lysis buffer (Cell Signaling Technology, Inc., Danvers, MA, USA) and protein extracts were dissolved in sample buffer (Cell Signaling Technology, Inc.) containing $2 \%$ sodium dodecyl sulfate (SDS), $50 \mathrm{mM}$ Tris-HCl, $100 \mathrm{mM}$ dithiothreitol (pH 6.80) and $10 \%$ glycerol. Protein samples $(30 \mu \mathrm{g})$ were separated by $10 \%$
SDS-polyacrylamide gel (Beyotime Institute of Biotechnology, Haimen, China) electrophoresis and electrotransferred onto a nitrocellulose membrane (EMD Millipore, Billerica, MA, USA). After blocking with 5\% non-fat milk in Tris-buffered saline solution (Beyotime Institute of Biotechnology) for $1 \mathrm{~h}$ at room temperature, blots were subsequently incubated with polyclonal goat anti-CRL (1:5,000; sc-18007), polyclonal rabbit anti-RAMP1 (1:5,000; sc-11379) and monoclonal mouse anti- $\beta$-catenin antibodies (1:5,000; sc-53483) overnight at $4^{\circ} \mathrm{C}$ (all purchased from Santa Cruz Biotechnology, Inc., Dallas, TX, USA). Following washing for 5 min 3 times with Tris-buffered saline, horseradish peroxidase (HRP)-conjugated polyclonal rabbit anti-mouse IgG (1:5,000; sc-358920), HRP-conjugated polyclonal goat anti-rabbit IgG (1:5,000; sc-2004) and HRP-conjugated polyclonal mouse anti-goat $\operatorname{IgG}(1: 5,000$; sc-2345) (all purchased from Santa Cruz Biotechnology, Inc., Dallas, TX, USA) were incubated with the membranes for $1 \mathrm{~h}$ 
A

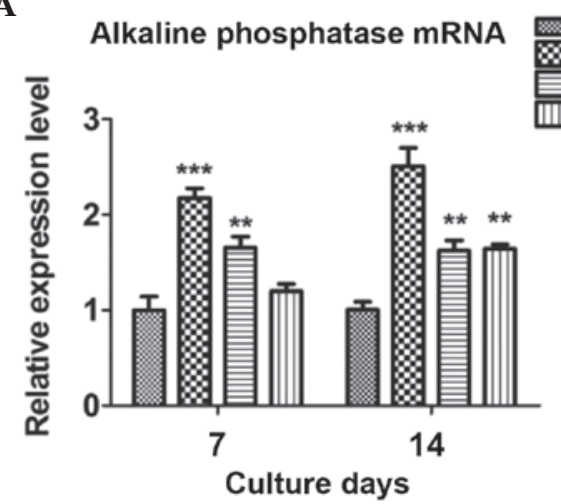

C

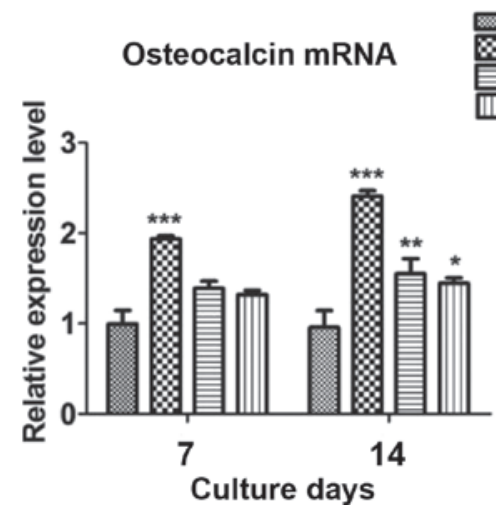

B

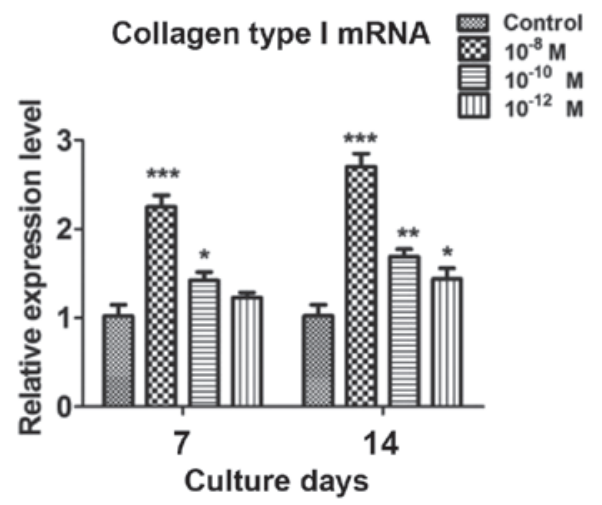

D
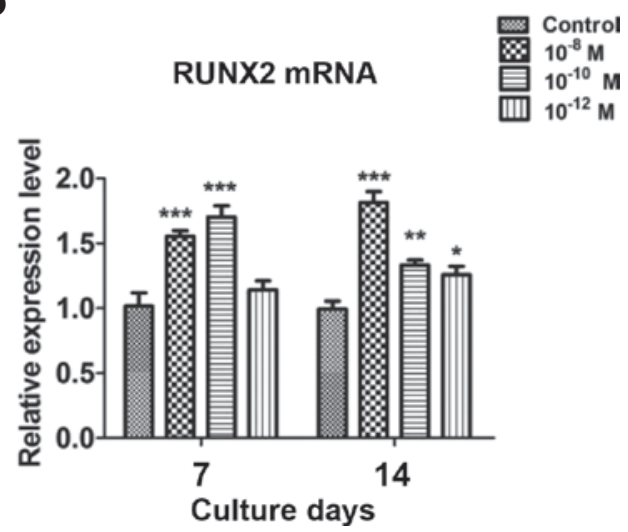

Figure 2. Effects of CGRP $\left(10^{-8}, 10^{-10}\right.$ or $\left.10^{-12}\right)$ on the expression of (A) alkaline phosphatase, (B) collagen type I, (C) osteocalcin and (D) Runx2 mRNA in bone marrow stromal stem cells at days 7 and 14 were assessed in induction medium using reverse-transcription quantitative polymerase chain reaction analysis. Values are expressed as the mean \pm standard error of the mean from three independent experiments. ${ }^{*} \mathrm{P}<0.05,{ }^{* *} \mathrm{P}<0.01$ and ${ }^{* * *} \mathrm{P}<0.001$ vs. Control. CGRP, calcitonin gene-related peptide.

at room temperature. An Imagestation 2000 MM (Eastman Kodak, Rochester, NY, USA) was then used for capturing images of the blots. Blots were stripped and re-probed with polyclonal goat anti-actin $(1: 500 ;$ sc-1616) and polyclonal rabbit anti- $\alpha$-tubulin (1:500; sc-5546) (both purchased from Santa Cruz Biotechnology, Inc.) antibodies to demonstrate equal loading and for normalization of the protein content among the groups. Densitometric analysis of the bands was performed using Molecular Imaging Software Version 4.0 (Eastman Kodak). Protein concentration was determined using an Immobilon Western Chemiluminescent HRP Substrate for enhanced chemiluminescence (EMD Millipore, Billerica, MA, USA).

Statistical analysis. Values are expressed as the mean \pm standard error of the mean. Statistical analyses were performed using SPSS software version 13.0 (SPSS, Inc., Chicago, IL, USA). One-way analysis of variance was used to compare mean values between groups. Comparisons among groups were performed using Dunnett's two-tailed t post-hoc test. $\mathrm{P}<0.05$ was considered to indicate a statistically significant difference.

\section{Results}

Morphological changes of BMSCs differentiating into osteoblasts. Following seven days of primary culture, BMSCs grew in spindle-like, triangular and polygonal shapes (Fig. 1A).
At passage 3 and beyond, cell growth was accelerated (Fig. 1B). After seven days of differentiation in the osteogenic medium, the cells grew slowly and were covered with calcium deposits (Fig. 1C). After 14 days of differentiation, alizarin red staining revealed that the cells displayed characteristics of osteoblasts and extracellular matrix mineralization (Fig. 1D).

CGRP receptors are expressed during osteoblastic differentiation of BMSCs. The expression of CRL and RAMP1 protein in BMSCs on days 7 and 14 of culture in osteogenic medium was assessed by western blot analysis (Fig. 1E and F). While CRL and RAMP1 protein expression was present in the osteogenic induction group as well as in the control group on days 7 and 14, expression levels were approximately two-fold increased in the induction group compared with those in the control group.

CGRP enhances the expression of osteoblastic marker genes in induced BMSCs. The effects of CGRP $\left(10^{-8}, 10^{-10}\right.$ and $\left.10^{-12} \mathrm{M}\right)$ on the differentiation of BMSCs were examined by assessing the mRNA expression of the early osteoblastic markers alkaline phosphatase and collagen type I as well as the late osteoblastic marker osteocalcin by using RT-qPCR analysis. Runx2, a transcriptional factor necessary for osteoblast differentiation, was also examined. Compared with the untreated group, CGRP treatment significantly increased the levels of osteoblastic markers at days 7 and 14 , with $10^{-8} \mathrm{M}$ CGRP exerting a greater effect than the lower concentrations (Fig. 2). 

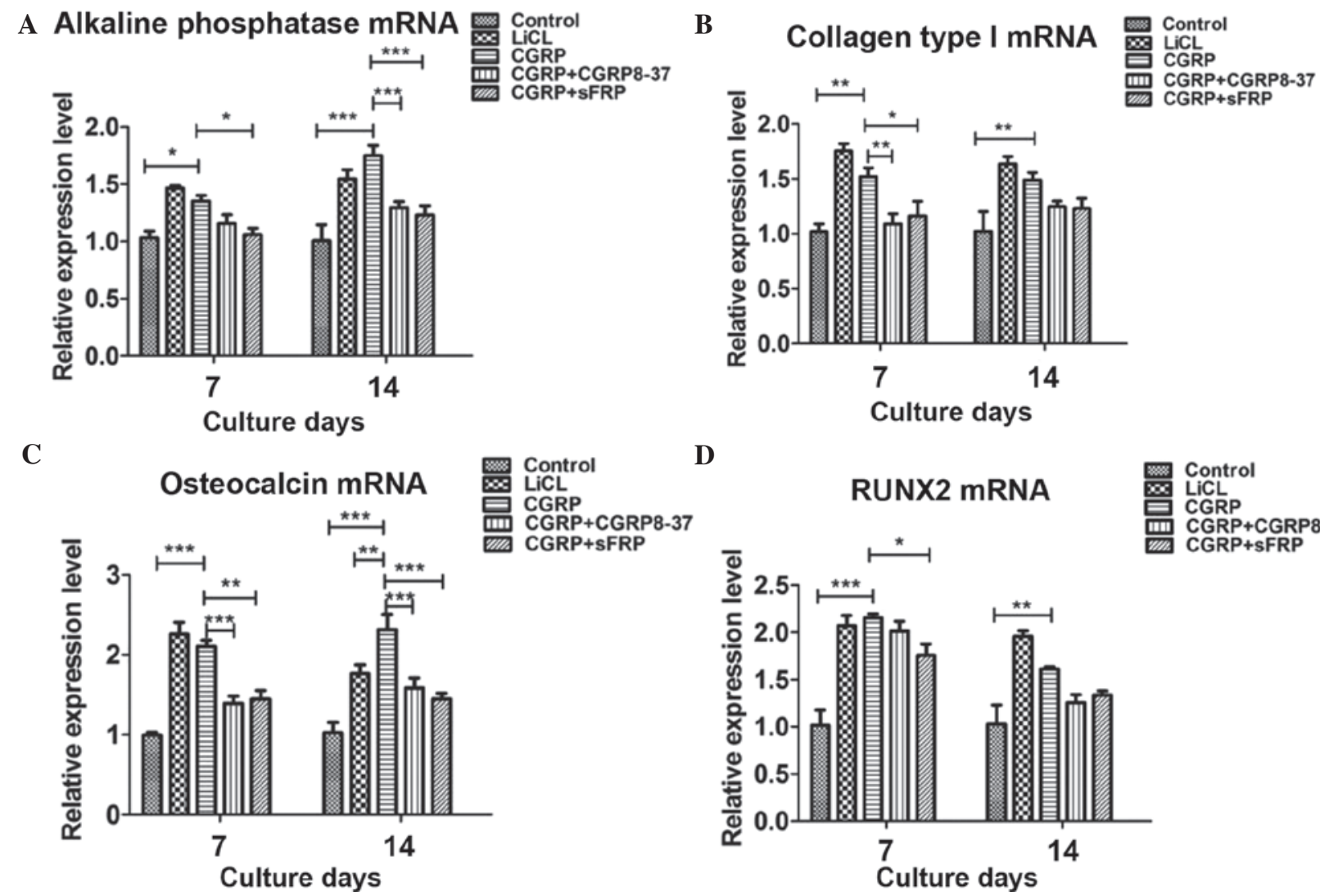

D

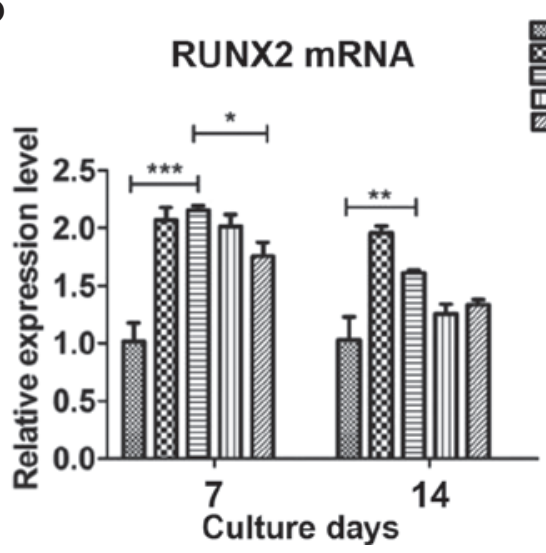

Figure 3. Effects of CGRP, LiCl, CGRP + CGRP8-37 and CGRP + sFRP on the expression of (A) alkaline phosphatase, (B) collagen type I, (C) osteocalcin and (D) Runx2 mRNA in bone marrow stromal stem cells were assessed in induction medium using reverse-transcription quantitative polymerase chain reaction analysis. Values are expressed as the mean \pm standard error of the mean from three independent experiments. ${ }^{*} \mathrm{P}<0.05,{ }^{* * *} \mathrm{P}<0.01,{ }^{* * * *} \mathrm{P}<0.001$ as indicated. CGRP, calcitonin gene-related peptide; sFRP, secreted frizzled-related protein (Wnt antagonist).

CGRP-mediated osteoblastogenesis of BMSCs proceeds via the Wnt/ $\beta$-catenin pathway. To assess the possible involvement of the Wnt/ $\beta$-catenin pathway in BMSC differentiation into osteoclasts, the effects of Wnt/ $\beta$-catenin pathway agonist LiCl, CGRP inhibitor CGRP8-37 and Wnt inhibitor sFRP on the expression of osteoblastic genes in induced BMSCs were examined in the absence or presence of CGRP. RT-qPCR revealed that CGRP $\left(10^{-8} \mathrm{M}\right)$ and $\mathrm{LiCl}$ alone significantly increased the expression of osteoblastic genes. Of note, pre-treatment with CGRP8-37 and sFRP significantly inhibited CGRP-induced expression of the osteoblastic markers by induced BMSCs (Fig. 3).

To further assess the involvement of the Wnt/ $\beta$-catenin signaling pathway, the mRNA expression of signaling molecules of this pathway, including c-myc, cyclin D1, Lef1, Tcf7 and $\beta$-catenin, was evaluated by RT-qPCR at days 7 and 14. Incubation of BMSCs with CGRP $\left(10^{-8}\right)$ and $\mathrm{LiCl}$ in the osteoinductive medium significantly increased the mRNA expression of c-myc, cyclin D1, Tcf7 and Lef1 on days 7 and 14, as compared with their expression in the control group. This upregulation was significantly inhibited by pre-treatment with CGRP8-37 or sFRP (Fig. 4A-D). However, the expression of $\beta$-catenin mRNA was not significantly affected in the experimental groups (Fig. 4E). Therefore, the protein expression of $\beta$-catenin in all experimental groups was examined by western blot analysis. The results revealed that CGRP $\left(10^{-8} \mathrm{M}\right)$ and $\mathrm{LiCl}$ increased the protein expression of $\beta$-catenin on days 7 and 14 compared with that in the control group. Furthermore, pre-treatment with CGRP8-37 or sFRP inhibited the CGRP-induced increase in $\beta$-catenin protein expression on days 7 and 14 (Fig. 4F).

\section{Discussion}

To the best of our knowledge, the present study was the first to demonstrate the involvement of the Wnt/ $\beta$-catenin signaling pathway in CGRP-mediated osteoblastic differentiation of BMSCs. Sharma et al reported that Rspo 1 is involved in bone remodeling and the activation of Wnt signaling in human as well murine in vitro osteoblast cell models (33). The present study used an agonist and a specific inhibitor of the Wnt/ $\beta$-catenin signaling pathway as well as an inhibitor of CGRP for mechanistic gain-and loss-of-function studies, and their effects on the expression of osteoblastic marker genes and the expression of Wnt signaling molecules in induced BMSCs were assessed.

CGRP acts at the cellular level by binding to its receptor CRL, following which it is able to regulate various biological functions, including bone remolding, pain, biological effects of human endothelial cells, cell differentiation and regulation of the cardiovascular system (6,34-36). However, to the best of our knowledge, changes in CRL and RAMP1 expression during the process of differentiation of BMSCs have remained to be fully elucidated. The present study discovered that RAMP1 and CRL protein were overexpressed in BMSCs undergoing osteoblastic differentiation. 

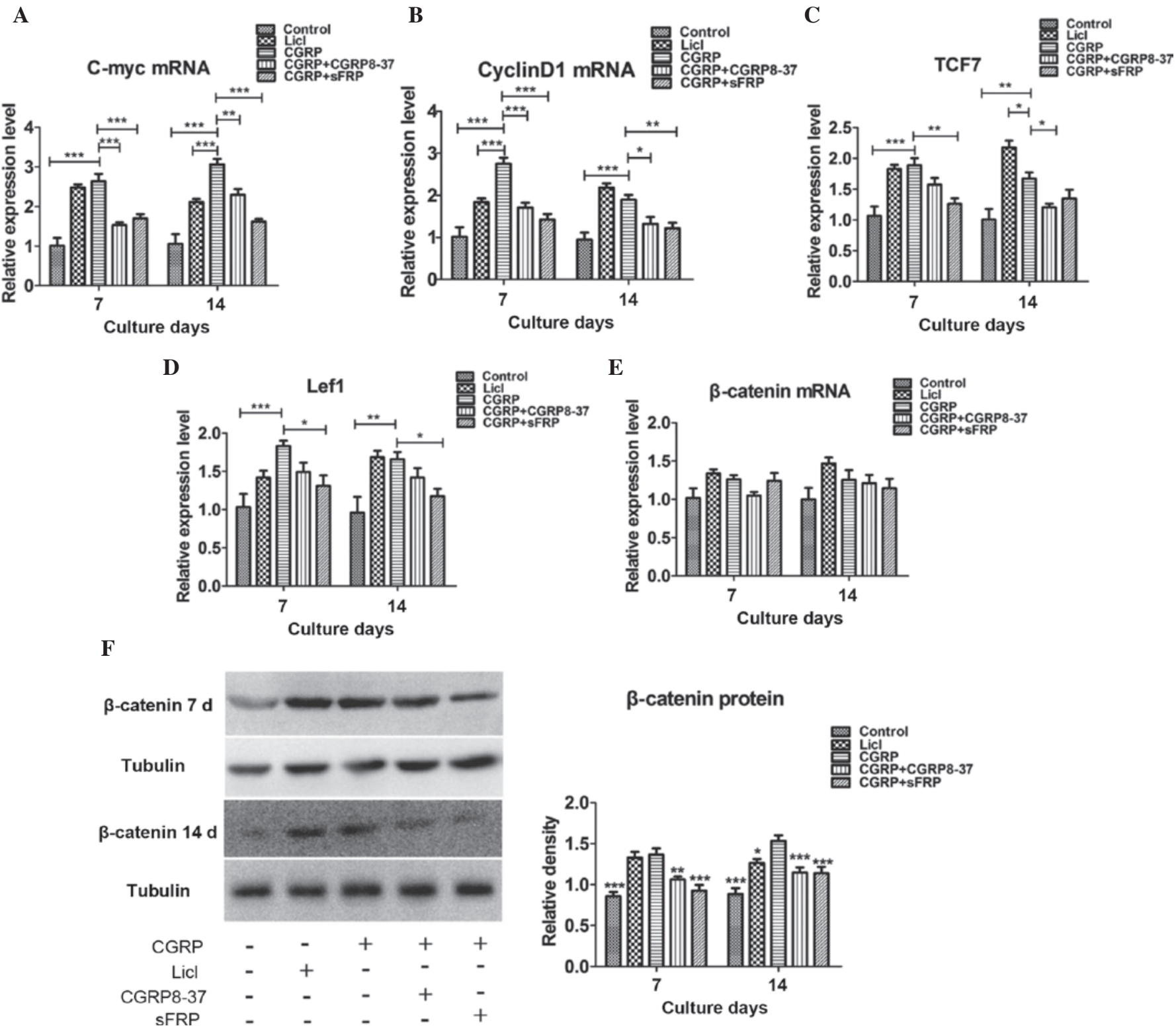

Figure 4. Effects of CGRP, LiCl, CGRP + CGRP8-37 and CGRP + sFRP on the mRNA expression of (A) c-myc, (B) cyclin D1, (C) Tcf7 (D) Lef1 and (E) $\beta$-catenin in BMSCs at days 7 and 14 were measured in induction medium using reverse-transcription quantitative polymerase chain reaction analysis. (F) $\beta$-Catenin protein expression in BMSCs at days 7 and 14 was measured in induction medium by western blot analysis. Values are expressed as the mean \pm standard error of the mean from three independent experiments. ${ }^{*} \mathrm{P}<0.05,{ }^{* *} \mathrm{P}<0.01$ and ${ }^{* * *} \mathrm{P}<0.001$ vs. CGRP. BMSC, bone marrow stromal stem cell; CGRP, calcitonin gene-related peptide; sFRP, secreted frizzled-related protein (Wnt antagonist).

The osteogenic effects of LiCl, CGRP + CGRP8-37 and CGRP + sFRP on BMSCs have not been previously described, to the best of our knowledge. Osteoblastic differentiation in vitro is directed by Runx 2 , the master transcription factor regulating bone formation, and BMSCs can differentiate towards the osteoblastic lineage, accompanied by the production of type I collagen and osteocalcin and increased alkaline phosphatase activity (37). The present study examined the osteoblastic differentiation of rat BMSCs and determined whether CGRP antagonist or Wnt antagonist sFRP were able to inhibit the inductive effects of CGRP on BMSCs.

When BMSCs were treated with CGRP $\left(10^{-8}, 10^{-10}\right.$ or $10^{-12} \mathrm{M}$ ) for 7 or 14 days, the expression of osteoblastic genes, including alkaline phosphatase, collagen type I, Runx2, and osteocalcin, was revealed to be induced, particularly at the highest concentration of CGRP $\left(10^{-8} \mathrm{M}\right)$. Furthermore, the stimulatory effects of CGRP on the osteoblastic differentiation of BMSCs was inhibited by CGRP receptor antagonist CGRP8-37 and the specific inhibitor of the Wnt/ $\beta$-catenin signaling pathway sFRP, suggesting that CGRP binds to CGRP receptors and activates the Wnt $/ \beta$-catenin signaling pathway, leading to the differentiation of BMSCs.

To further study the roles of the Wnt/ $\beta$-catenin signaling pathway in the stimulatory effects of CGRP on the osteoblastic differentiation of BMSC, the effects of CGRP, CGRP8-37 and sFRP on the expression of genes involved in the Wnt $/ \beta$-catenin signaling pathway in BMSCs were also examined. CGRP was found to significantly increase the expression of the Wnt/ $\beta$-catenin signaling molecules c-myc, cyclin D1, Tcf7 and Lef1 at the mRNA level. $\beta$-catenin, which is crucial for 
the activation of $\mathrm{Wnt} / \beta$-catenin signaling, was obviously affected at the mRNA level; however, differences between the experimental groups were not statistically significant. Of note, CGRP significantly enhanced the protein expression of $\beta$-catenin at 7 and 14 days, which was inhibited by CGRP8-37 and sFRP. The greater effects of CGRP and the inhibitors CGRP8-37 and SFRP on $\beta$-catenin at the protein level compared to those at the mRNA level may indicate that the enhancement of $\beta$-catenin signaling may be complex. For instance, activation of $\beta$-catenin via phosphorylation rather than upregulation of its gene expression may be involved in the activation of the $\mathrm{Wnt} / \beta$-catenin signaling pathway.

The role of Tcf7/Lef1 in the Wnt/ $\beta$-catenin signaling pathway is controversial. While certain studies suggested that Tcf7 acts as a repressor as well as an activator, and that Lef1 is usually an activator but occasionally a repressor, other studies have reported that Lef1 and Tcf7 cooperatively activate the expression of Wnt/ $\beta$-catenin signaling target genes to promote cell proliferation in the dorsal midbrain (38-40). The present study found that treatment of BMSCs with CGRP $\left(10^{-8} \mathrm{M}\right)$ for 7 and 14 days led to an increased expression of Lef 1 and Tcf7. Therefore, it is indicated that Lef 1 and Tcf7 may be involved in the CGRP-induced activation of Wnt/ $\beta$-catenin signaling in BMSCs.

The present study also assessed the expression of two Wnt target genes, c-myc and cyclin D1, which were markedly increased in BMSCs following CGRP treatment, which was significantly reduced by pre-incubation with CGRP inhibitor, indicating that c-myc and cyclin D1 may be involved in the process of osteoblastic differentiation of BMSCs, which was in turn enhanced by activation of the Wnt $/ \beta$-catenin signaling pathway. All of these results suggested that BMSC differentiation into osteoblasts by stimulation with CGRP proceeds via the $\mathrm{Wnt} / \beta$-catenin signaling pathway.

In conclusion, the present study demonstrated that the CGRP ligands CRL and RAMP1 were overexpressed throughout the osteoblastic differentiation of BMSCs, and that their interaction with CGRP was likely to have stimulated this differentiation process. The canonical Wnt signaling pathway was indicated to contribute to this process.

\section{References}

1. Bjurholm A, Kreicbergs A, Brodin E and Schultzberg $\mathrm{M}$ : Substance P- and CGRP-immunoreactive nerves in bone. Peptides 9: 165-171, 1988.

2. Imai S and Matsusue Y: Neuronal regulation of bone metabolism and anabolism: Calcitonin gene-related peptide-, substance $\mathrm{P}$ - and tyrosine hydroxylase-containing nerves and the bone. Microsc Res Tech 58: 61-69, 2002.

3. Kawase T, Okuda K and Burns DM: Immature human osteoblastic MG63 cells predominantly express a subtype 1-like CGRP receptor that inactivates extracellular signal response kinase by a cAMP-dependent mechanism. Eur J Pharmacol 470: 125-137, 2003.

4. Schinke T, Liese S, Priemel M, Haberland M, Schilling AF, Catala-Lehnen P, Blicharski D, Rueger JM, Gagel RF, Emeson RB and Amling M: Decreased bone formation and osteopenia in mice lacking alpha-calcitonin gene-related peptide. J Bone Miner Res 19: 2049-2056, 2004.

5. Togari A, Arai M, Mizutani S, Mizutani S, Koshihara Y and Nagatsu T: Expression of mRNAs for neuropeptide receptors and beta-adrenergic receptors in human osteoblasts and human osteogenic sarcoma cells. Neurosci Lett 233: 125-128, 1997.
6. Tuo Y, Guo X, Zhang X, Wang Z, Zhou J, Xia L, Zhang Y, Wen J and Jin D: The biological effects and mechanisms of calcitonin gene-related peptide on human endothelial cell. J Recept Signal Transduct Res 33: 114-123, 2013.

7. Uzan B, de Vernejoul MC and Cressent M: RAMPs and CRLR expressions in osteoblastic cells after dexamethasone treatment. Biochem Biophys Res Commun 321: 802-808, 2004.

8. Villa I, Mrak E, Rubinacci A, Ravasi F and Guidobono F: CGRP inhibits osteoprotegerin production in human osteoblast-like cells via cAMP/PKA-dependent pathway. Am J Physiol Cell Physiol 291: C529-C537, 2006.

9. Wimalawansa SJ: Calcitonin gene-related peptide and its receptors: Molecular genetics, physiology, pathophysiology and therapeutic potentials. Endocr Rev 17: 533-585, 1996.

10. Wimalawansa SJ: Amylin, calcitonin gene-related peptide, calcitonin and adrenomedullin: A peptide superfamily. Crit Rev Neurobiol 11: 167-239, 1997.

11. Fang Z, Yang Q, Xiong W, Li GH, Liao H, Xiao J and Li F: Effect of CGRP-adenoviral vector transduction on the osteoblastic differentiation of rat adipose-derived stem cells. PLoS One 8: e72738, 2013

12. Wang YS, Wang YH, Zhao GQ and Li YB: Osteogenic potential of human calcitonin gene-related peptide alpha gene-modified bone marrow mesenchymal stem cells. Chin Med J (Engl) 124: 3976-3981, 2011.

13. Xu J, Kauther MD, Hartl J and Wedemeyer C; Study was performed at the University of Duisburg-Essen, Germany: Effects of alpha-calcitonin gene-related peptide on osteoprotegerin and receptor activator of nuclear factor- $\mathrm{\kappa} B$ ligand expression in MG-63 osteoblast-like cells exposed to polyethylene particles. J Orthop Surg Res 5: 83, 2010.

14. Yoo YM, Kwag JH, Kim KH and Kim $\mathrm{CH}$ : Effects of neuropeptides and mechanical loading on bone cell resorption in vitro. Int J Mol Sci 15: 5874-5883, 2014.

15. Ballica R, Valentijn K, Khachatryan A, Guerder S, Kapadia S, Gundberg C, Gilligan J, Flavell RA and Vignery A: Targeted expression of calcitonin gene-related peptide to osteoblasts increases bone density in mice. J Bone Miner Res 14: 1067-1074, 1999.

16. Huebner AK, Schinke T, Priemel M, Schilling S, Schilling AF, Emeson RB, Rueger JM and Amling M: Calcitonin deficiency in mice progressively results in high bone turnover. J Bone Miner Res 21: 1924-1934, 2006.

17. Kim SY, Kim S, Yun-Choi HS and Jho EH: Wnt5a potentiates U46619-induced platelet aggregation via the PI3K/Akt pathway. Mol Cells 32: 333-336, 2011.

18. Zheng Q, Chen P, Xu Z, Li F and Yi XP: Expression and redistribution of $\beta$-catenin in the cardiac myocytes of left ventricle of spontaneously hypertensive rat. J Mol Histol 44: 565-573, 2013

19. Lee JH, Kim BG, Ahn JM, Park HJ, Park SK, Yoo JS, Yates JR III and Cho JY: Role of PI3K on the regulation of BMP2-induced beta-Catenin activation in human bone marrow stem cells. Bone 46: 1522-1532, 2010.

20. Li J, Li J and Chen B: Oct4 was a novel target of Wnt signaling pathway. Mol Cell Biochem 362: 233-240, 2012.

21. Liu Y, Liu Y, Zhang R, Wang X, Huang F, Yan Z, Nie M, Huang J, Wang Y, Wang Y, et al: All-trans retinoic acid modulates bone morphogenic protein 9-induced osteogenesis and adipogenesis of preadipocytes through $\mathrm{BMP} / \mathrm{Smad}$ and $\mathrm{Wnt} / \beta$-catenin signaling pathways. Int J Biochem Cell Biol 47: 47-56, 2014.

22. MacDonald BT, Tamai $\mathrm{K}$ and He X: Wnt/beta-catenin signaling: Components, mechanisms and diseases. Dev Cell 17: 9-26, 2009.

23. Peterson-Nedry W, Erdeniz N, Kremer S, Yu J, Baig-Lewis S and Wehrli M: Unexpectedly robust assembly of the Axin destruction complex regulates Wnt/Wg signaling in Drosophila as revealed by analysis in vivo. Dev Biol 320: 226-241, 2008.

24. Salins P, Shawesh S, He Y, Dibrov A, Kashour T, Arthur G and Amara F: Lovastatin protects human neurons against Abeta-induced toxicity and causes activation of beta-catenin-TCF/LEF signaling. Neurosci Lett 412: 211-216, 2007.

25. Sun YC: Examination of effects of GSK3beta phosphorylation, beta-catenin phosphorylation and beta-catenin degradation on kinetics of Wnt signaling pathway using computational method. Theor Biol Med Model 6: 13, 2009.

26. Weng X, Lin P, Liu F, Chen J, Li H, Huang L, Zhen C, Xu H, Liu X, Ye H and Li X: Achyranthes bidentata polysaccharides activate the Wnt/ $\beta$-catenin signaling pathway to promote chondrocyte proliferation. Int J Mol Med 34: 1045-1050, 2014. 
27. Wen X, Cawthorn WP, MacDougald OA, Stupp SI, Snead ML and Zhou Y: The influence of Leucine-rich amelogenin peptide on MSC fate by inducing Wnt10b expression. Biomaterials 32: 6478-6486, 2011.

28. Georgiou KR, King TJ, Scherer MA, Zhou H, Foster BK and Xian CJ: Attenuated Wnt/ $\beta$-catenin signalling mediates methotrexate chemotherapy-induced bone loss and marrow adiposity in rats. Bone 50: 1223-1233, 2012.

29. Guo J, Liu M, Yang D, Bouxsein ML, Saito H, Galvin RJ, Kuhstoss SA, Thomas CC, Schipani E, Baron R, et al: Suppression of Wnt signaling by Dkk1 attenuates PTH-mediated stromal cell response and new bone formation. Cell Metab 11: 161-171, 2010.

30. Tamura M, Sato MM and Nashimoto M: Regulation of CXCL12 expression by canonical Wnt signaling in bone marrow stromal cells. Int J Biochem Cell Biol 43: 760-767, 2011.

31. Hu HM, Yang L, Wang Z, Liu YW, Fan JZ, Fan J, Liu J and Luo ZJ: Overexpression of integrin a2 promotes osteogenic differentiation of hBMSCs from senile osteoporosis through the ERK pathway. Int J Clin Exp Pathol 6: 841-852, 2013.

32. Livak KJ and Schmittgen TD: Analysis of relative gene expression data using real-time quantitative PCR and the 2(-Delta Delta C(T)) Method. Methods 25: 402-408, 2001.

33. Sharma AR, Choi BS, Park JM, Lee DH, Lee JE, Kim HS, Yoon JK, Song DK, Nam JS and Lee SS: Rspo 1 promotes osteoblast differentiation via Wnt signaling pathway. Indian J Biochem Biophys 50: 19-25, 2013.
34. Bloom AP, Jimenez-Andrade JM, Taylor RN, Castañeda-CorralG, Kaczmarska MJ, Freeman KT, Coughlin KA, Ghilardi JR, Kuskowski MA and Mantyh PW: Breast cancer-induced bone remodeling, skeletal pain and sprouting of sensory nerve fibers. J Pain 12: 698-711, 2011.

35. Eberhardt M, Dux M, Namer B, Miljkovic J, Cordasic N, Will C, Kichko TI, de la Roche J, Fischer M, Suárez SA, et al: H2S and NO cooperatively regulate vascular tone by activating a neuroendocrine HNO-TRPA1-CGRP signalling pathway. Nat Commun 5: 4381, 2014.

36. Sample SJ, Hao Z, Wilson AP and Muir P: Role of calcitonin gene-related peptide in bone repair after cyclic fatigue loading. PLoS One 6: e20386, 2011.

37. Shui C, Spelsberg TC, Riggs BL and Khosla S: Changes in Runx2/Cbfa1 expression and activity during osteoblastic differentiation of human bone marrow stromal cells. J Bone Miner Res 18: 213-221, 2003.

38. Hoppler S and Kavanagh CL: Wnt signalling: Variety at the core. J Cell Sci 120: 385-393, 2007.

39. Lee JE, Wu SF, Goering LM and Dorsky RI: Canonical Wnt signaling through Lef 1 is required for hypothalamic neurogenesis. Development 133: 4451-4461, 2006.

40. Shimizu N, Kawakami K and Ishitani T: Visualization and exploration of Tcf/Lef function using a highly responsive Wnt/ $\beta$-catenin signaling-reporter transgenic zebrafish. Dev Biol 370: 71-85, 2012. 